\title{
Hanfu Culture Network Creative Industry Research
}

\section{Chenxi Zhang}

School of Humanities and Foreign Languages, China Metrology University, Hangzhou, Zhejiang Province, China

596975376@qq.com

Keywords: Hanfu Industry, Hanfu Culture Communication, Taobao Data.

\begin{abstract}
Hanfu culture industry originated from the Internet. It has experienced rapid development from scratch in the past ten years. By 2018, its industrial scale has reached one billion. This paper aims to give a true overview of the current status of the Hanfu culture industry and analyze its unique network industry model. This article provides an overview of the present situation of Hanfu culture industry. Firstly, it defines the scope of Hanfu's research. Then the author applies the British "Value Chain Analysis Method" of Charles Randy in the Hanfu culture industry to analyze the unique industrial model of Hanfu network industry. Through the data crawled from the three platforms of Taobao, Weibo and Tik Tok, a quantitative analysis was made on the communication power of the Hanfu culture industry. The innovation of this paper is to analyze the shortcomings in the Hanfu network industry with the crawled data, summarize the problems in the previous papers, and analyze and predict the trend of the future Hanfu network culture industry.
\end{abstract}

\section{汉服文化网络创意产业研究}

\author{
张晨曦 \\ 中国计量大学人文与外语学院, 杭州, 浙江, 中国 \\ 596975376@qq.com
}

关键词: 汉服产业 汉服文化传播 淘宝数据

中文摘要. 汉服文化产业发源于互联网, 十年来经历了从无到有的迅速发展, 截至 2018 年, 其产业规模已达十亿。本文旨在对目前的汉服文化产业现状进行一个真实的概述, 剖析其独 特的网络产业模式。本文是对汉服文化产业现状的概述, 先界定了汉服的研究范围, 接着笔 者将英国的查尔斯·兰蒂的“价值链分析法”运用在汉服文化产业中剖析汉服网络产业独特的 模式, 通过从淘宝、微博、抖音三大平台爬取的数据对汉服文化产业的传播力做了一个量化 分析。本文创新之处在于结合爬取的数据分析汉服网络产业中存在的弊病, 对前文中的问题 进行总结，并对未来汉服网络文化产业的趋势做了分析预测。

\section{1.引言}

《左传·注疏》中有云“中国有礼仪之大，故称夏。有章服之美，谓之华。”汉服作为一种 服饰承载了中国文化的沉淀, 进入 21 世纪快消时代, 汉服却在互联网媒体的推动下, 在网络 上以一种定金预付一一付清尾款一一最终发货的“时间慢周期长”类似“霸王条款”的方式获得 了蓬勃发展，据汉服资讯统计，2018 年新的汉服商家持续增长，淘宝店能正常打开的汉服商 家已达 815 家，比 2017 年增长了 $24.43 \%$, 汉服商家遍布全国 28 个省、区、直辖市，其中长 三角、珠三角、四川省是三大主要的区域, 汉服产业总规模已达 10 亿元。汉服文化的传播与 
汉服产业总体蓬勃发展，但繁荣背后其中仍然存在知识产权等山寨问题值得探讨。

\section{2.汉服文化产业现状概述}

\section{1 汉服概述}

“汉服”一词据可考文献最早见于《马王堆三号墓造册》：“美人四人，其二人楚服，二人 汉服” 这里的“汉服”本义指的是汉朝人的服饰，而“汉服”演变至今，发生了词义的扩大被赋 予了新义，如今的“汉服”是概括了明朝及其以前朝代汉族传统服饰形成的“泛概念”，是以华 夏文化为核心，有区别于其他族类独特的服饰风貌和配饰体系。因此，汉服的溯源可追溯至 黄帝时期，《周易·系辞》：黄帝、尧、舜，垂衣裳而天下治。华夏汉族人自此拥有了自己独 特的民族服饰。笔者将目前学界对汉服的定义归类分为三种:

表 1 汉服概念界定

\begin{tabular}{|l|l|}
\hline 汉服 & $\begin{array}{l}\text { (1) 专指历史上汉王朝的服饰，在时间上仅限汉朝，范围较窄。 } \\
\text { 主要包括“上衣下裳制”“深衣制”“襦裙制”等。 }\end{array}$ \\
\cline { 2 - 3 } & $\begin{array}{l}\text { (2) 作为“汉民族传统服饰的简称”，包括不同历史时期分类众多但核心 } \\
\text { 都是具有汉民族精神内核的服饰，包括曲裾、魏晋风度、唐代齐胸襦裙、 } \\
\text { 宋代马面裙、明制等，历时一千多年。 }\end{array}$ \\
& $\begin{array}{l}\text { (3) 带有“汉元素”的仿古特色衣饰，是将现代衣服的便利和“汉元素”的 } \\
\text { 部分特征相结合，是现代新兴的非传统形制的服装。 }\end{array}$ \\
\hline
\end{tabular}

本文的汉服文化产业是从（2）（3）的角度进行数据的统计与分析，（1）蕴含在（2） 中, (2) 与 (3) 是相交关系, 共同拥有的部分是汉元素。

\section{2 汉服文化产业现状概述}

英国的查尔斯·兰蒂将“价值链分析法”应用在文化产业的调查研究之中, 由此提出了构成 文化产业基本价值链的五个环节，笔者将此同样细化在汉服文化产业生产中:

（1）创意的成型：这是创造性的本身，从知识产权的角度来说，创造的意象必然要与专 利、版权和商标联系在一起。笔者调研了淘宝 16 家销量最高店铺的原创设计, 汉服与其他淘 宝产品在页面上呈现最大的不同就在于非常注重保护自己的知识产权, 其主要体现在衣服纹 样上，页面展示除了样衣的整体外观通常还会放大衣服的纹样细节来保护自己的原创设计。 这是由于汉服的种类主要分为曲裾、魏晋风度、唐代齐胸襦裙、宋代马面裙、明制, 那么同 种种类的汉服只能在衣服的纹样上进行创意的设计。

（2）汉服设计落地成产品: 在这个过程中, 汉服有着与众不同的生产方式, 由于汉服一 开始是作为一种小众爱好群体的圈内文化, 且因为汉服相比普通衣服的不便性, 所以淘宝网 上的汉服绝大多数采取设计图样一一生产原衣（数量非常少）——模特拍照一一淘宝店铺 这样的模式来进行一套汉服从创意到产品的成型。

（3）汉服文化产品的流通：代理商、发行人会在其中促进沟通传播，具体在汉服产业上 有一个很特别的点就是汉服的“定金预付”机制, 在这个快消品泛滥的时代, 普通人很难想象 需要预付一百的定金还需要等上最少一个月，付清尾款后才能发货。汉服的“定金预付机制” 是淘宝网上架——买家预付定金一一卖家在这一个月里生产这一批次的汉服一一一个月后通 知买家付清尾款——买家付清尾款——卖家发货——买家收到汉服。

（4）汉服的发送机构: 汉服兴起于网络, 在目前的汉服市场上，汉服文化产业主要的消 费方式仍然是以淘宝网为首的网络交易占据绝大多数的份额。淘宝网作为目前国内最大的电 商平台，不仅为汉服产业的落地提供了切实可行的通道，还催生了一批“汉服爱豆”，顾名思 义也就是专门穿汉服的模特, 与淘宝的其他模特相比, 汉服模特的个人知名度相对高很多, 
且都具有很强的品牌专一性, 如小豆冦儿、十里等。在汉服爱好者里都具有很高的知名度, 这些汉服模特在漫展上进行签售, 以嘉宾的身份参加活动, 在汉服爱好者里形成了一种“类爱 豆文化”。这种“类爱豆文化”具体表现在微博和抖音上就是通俗所说的“网红大 V”，截至笔者 发稿, 十三余店铺的小豆冦儿在微博上拥有粉丝 264 万, 抖音粉丝 174.2 万，抖音最热视频 作品获得 161.9 万个赞。而这种形式的“汉服爱豆”还有很多。

（5）最终汉服爱好者的接受: 批评家的角色——买家淘宝评价, 市场营销——卖家用微 信红包来鼓励买家给予五星好评和返图。这一环节是汉服文化产业链的终端, 传播学家麦奎 尔指出产品普通受众和爱好者是完全不同的两种受众, 在传播方式上, 两种受众的传播媒介 也是不同的。汉服文化产业的普通受众也就是目前大众媒介的受众，如抖音、微博、小红书 等。通过大众媒介接受汉服文化产品时, 普通受众人数多, 规模大, 年龄分布广, 具有分散 性、匿名性，普通受众在汉服文化产品的“解码”过程中很大程度上取决于其知识背景和对传 统文化的美感审视, 在这一过程中, 审美感官趋于一致的普通受众会渐渐由此变为汉服爱好 者, 据汉服咨询 2018 年的问卷调查统计，在汉服同袍中，女性占总数的 $88.21 \%$, 相比 2017 年的调查统计, 百分比略有下降, 男性汉服爱好者占总数的 $11.79 \%$, 微增, 男女汉服爱好者 性别比例接近一比九, 由此可见，女性汉服爱好者将在一段时间内仍为市场的主力军。而女 性消费者在网购消费时极具网络特色, 是粉丝经济的重要受众, 她们通常会在网上做攻略, 喜欢接受网红大 $\mathrm{V}$ 的“安利”，也由此支撑了“汉服爱豆”现象的产生。

\section{3.汉服文化产业的传播影响及其意义}

为量化汉服网络产业的文化传播度和影响力, 笔者选取了 2019 年 $9 、 10$ 月份淘宝上热度 最高的十六个淘宝店铺, 从目前影响力最大且具有领域代表性的三个网络平台: 淘宝、微博、 抖音爬取数据。接着, 为了达到量化网络影响力的目的, 笔者从这三个网络平台上细化出六 个具体的数据统计, 分别是: 淘宝店铺的粉丝数、淘宝店铺销量最高的宝贝月销、微博粉丝 数量、微博热门内容最高转发、抖音粉丝数量和抖音累计获赞（附表 2）:

表 22019 年 10 月三大平台汉服影响力数据

\begin{tabular}{|l|l|l|l|l|l|l|}
\hline 汉服品牌 & $\begin{array}{l}\text { 店铺粉丝 } \\
\text { 数 }\end{array}$ & $\begin{array}{l}\text { 销量最高 } \\
\text { 宝微博粉丝 }\end{array}$ & $\begin{array}{l}\text { 微博热门 } \\
\text { 内容最高 } \\
\text { 转发 }\end{array}$ & $\begin{array}{l}\text { 抖音粉 } \\
\text { 丝 }\end{array}$ & $\begin{array}{l}\text { 抖音累 } \\
\text { 计获赞 }\end{array}$ \\
\hline 十三余 & 273 万 & 2 万+ & 264 万 & 2.6 万 & 174.2 & 1004.8 万 \\
\hline 汉尚华莲 & 260 万 & 2056 & 34 万 & 1.3 万 & 156.1 万 & 1658.8 万 \\
\hline 京渝堂 & 43.6 万 & 28 & 3 万 & 72 & 无 & 无 \\
\hline 重回汉唐 & 211 万 & 1640 & 20 万 & 3462 & 28.6 万 & 162.2 万 \\
\hline 汉衣晟道 & 60.2 万 & $5500+$ & 2.6 万 & 40 & 1.2 万 & 7672 \\
\hline 钟灵记 & 201 万 & 3238 & 12 万 & 1880 & 25.8 万 & 131.5 万 \\
\hline 梨花渡 & 210 万 & 2954 & 7 万 & 1797 & 18.5 万 & 93 万 \\
\hline 池夏 & 98.5 万 & 4213 & 10.1 万 & 1940 & 18 万 & 111.6 万 \\
\hline 汉韵阁 & 27.5 万 & 1532 & 8855 & 1156 & 无 & 无 \\
\hline 兰若庭 & 172 万 & 8 万+ & 28 万 & 3.7 万 & 5 万 & 10 万 \\
\hline 南雅集 & 46.9 万 & $6500+$ & 2.6 万 & 15 & 3.5 万 & 9.8 万 \\
\hline 她说汉服 & 74.8 万 & 1 万+ & 12.8 万 & 1212 & 6.8 万 & 15.9 万 \\
\hline 花朝记 & 152 万 & 1422 & 8 万 & 1577 & 15.9 万 & 78.5 万 \\
\hline 织羽集 & 280 万 & 524 & 12 万 & 3852 & 17 万 & 111.9 万 \\
\hline 司南阁 & 88.9 万 & 433 & 23 万 & 1588 & 15.9 万 & 94.2 万 \\
\hline 都城南庄 & 123 万 & 678 & 4 万 & 1188 & 7.2 万 & 25.9 万 \\
\hline
\end{tabular}




\section{1 汉服文化产业的传播影响力}

根据数据统计分析, 可以很清晰的看到这 16 个淘宝店铺的粉丝数都在 40 万以上, 与其 他品类店铺相比也是相当具有影响力的。横向比较, 淘宝店铺作为汉服产业的主营平台具有 绝对领先的地位, $37.5 \%$ 的淘宝店铺粉丝数超过 200 万, 拥有 100 200 万淘宝店铺粉丝的店铺 占比 $18.75 \%$, 拥有 100 万以下粉丝的淘宝店铺占比 $43.75 \%$, 通过表四, 可以清晰的看到粉 丝一百万以上的淘宝店铺占比过半, 更有一个值得关注的点是拥有两百万以上粉丝的店铺远 超拥有 100 200 万粉丝的店铺数量, 几乎是其两倍。与淘宝粉丝数形成鲜明对应的还有抖音 作品的累计获赞量, 十六个品牌汉服中仅有十三余和汉尚华莲在抖音累计获赞中突破一千万, 其余品牌店家相差近乎十倍。

这个现象笔者认为正是应证了笔者在前文中提到的汉服爱豆现象, 受网络自媒体的影响, 网络红人和大 IP 的影响力在网络销售中发挥着越来越重要的作用, 汉服商家正是看到了这一 点, 于是受市场导向影响开始推出联名汉服, 池夏携手网络长篇小说《九州缥纱录》推出十 款联名汉服; 十三余联名古风歌手银临, 根据其音乐作品《流光记》和《棠梨煎雪》推出闺 蜜汉服; 汉尚华莲携手漫画家夏达, 根据其漫画作品《拾遗录》推出三款联名汉服; 流烟昔 泠联名 2019 暑假爆款网剧《陈情令》推出了五款联名汉服; 都城南庄和携手同为网络热播剧 的《长安十二时辰》推出五款联名汉服; 浅岱江南携手爆火网络小说 IP《诛仙》推出三款联 名汉服。这些现象都逐渐表明了一种趋势, 汉服产业正在渐渐跳脱出传统意义上的汉服本体 产业, 从汉服文化前向关联的产业: 汉服原布料、服装设计和传统织造工艺, 逐渐转向汉服 文化后向关联产业：版权产业、生活商业服务类，如汉服联名古风网络小说电视剧，杭州街 头小巷的汉服体验馆和一些展示中华文化的商业活动等。

\section{2 汉服文化产业的兴起的意义}

天猫《2018 年汉服消费人群报告》显示, 2018 年购买汉服的人数比上一年足足增长了 $92 \%$ 。汉服文化产业正在以超出想象的方式快速地在网络上传播, 这种传播不仅让中国传统 文化以汉服的形式重新焕发生机, 还让越来越与国际接轨的民众更直接地感受中华文化的鬼 力。表 2 的数据可以很明显的反映这个情况, 在微博粉丝中仅有十三余的微博粉丝 264 万傲 视群雄, 第二名汉尚华莲仅为 34 万, 其中的差距笔者在进行微博内容调研时找到了答案 十三余的小豆荍儿将中国传统的文化知识, 如《山海经》《庄子》融入汉服的设计中, 在进 行汉服产品介绍时, 她将这种知识理念传播给粉丝, 老庄的逍遥、鲲鹏的花纹, 这种带着文 化厚度的产品用中国传统的文化知识超越了同类竞品。

汉服不仅仅是一件独具民族特色的服饰, 其背后所蕴含的更为深刻的是我们中华民族的 文化内涵和历史传承。2019 年 10 月 26-10月 29 日西塘汉服文化周第七届如约而至, 这场由 方文山和徐娇发起的西塘汉服文化周又迎来了人流的高峰, 汉服由于其日益增长的影响力已 经逐渐从传统的漫展 ACG 中独立出来形成自己的专场, 甚至在 2019 年 9 月的淘宝造物节上 汉服也作为中国文化的板块占据了十分大的比重。电视剧《知否知否应是绿肥红瘦》中就借 用了宋代的汉服, 配以自然的烛火光, 向观众展示了我国宋代的风土人情与文化风貌, 该剧 拿下韩国中华 TV 收视率第一名, 可见汉服后关联产业的发展兴起, 而这种后关联产业的兴 起对我国文化“走出去”发挥着非常重要的积极意义。

\section{4.汉服文化产业的问题}

\section{1“知山穿山”的不良风气和“矫枉过正”}

“知山穿山”是汉服文化中一个具有代表性的圈内用语, 指的是明知道这个汉服是山寨别 人家的设计，但因为其便宜的价格依然购买山寨的衣服。“知山穿山”产生的背景是汉服近十 年来快速发展和前期相关法律不健全, 加上汉服迷年龄的普遍低龄化, 对版权没有正确的认 
识, 汉服是我国传统文化的瑰宝, 形制上是申请不了版权的, 但是商家设计的样式花纹是受 到知识产权的保护的。因此, 我们必须认识到山寨是对知识产权的侵犯, 可以通过法律的途 径解决。但也因为汉服圈的低龄化导致任何风气都容易“矫枉过正”，这种歧视他人穿“山寨” 的汉服逐渐演变为歧视穿便宜汉服的风气, 这种风气造成了非常消极的影响, 引起普通消费 者的反感, 阻碍了汉服文化的进一步传播扩大, 因此, 要给予其正确价值观的指引。

\section{2 单一的销售渠道}

笔者在网络调研中发现, 淘宝、微博和抖音都有购买窗口通道, 但在网络销售中, 淘宝 一家独大, 缺乏平台的竞争性, 即使是同为阿里系的升级版天猫, 同品牌汉服销售量也相比 淘宝持续走低。长此以往, 这种单一的销售模式恐会带来僵化和升级困难的弊病, 笔者对此 表示忧虑。

\section{5.结束语}

岂曰无衣？与子同袍。王于兴师，修我甲兵。与子偕行。汉服爱好者们互称“同袍”，以 中华文化为核心, 以汉服为表征, 带动了我国传统文化的传播和汉服文化产业的兴起。通过 对汉服文化产业的研究, 笔者认为汉服将会逐渐从舞台融入人民的生活, 如今在杭州这个城 市已经可以处处看见穿着汉服的女生, 尤其是在西湖边和灵隐寺附近。这种汉服走入生活的 趋势，正是汉服文化产业兴起最有力的证明。

淘宝店铺作为汉服网络产业最重要的销售渠道可以预期还将存在很长一段时间, 在维稳 的基础上商家也许可以试着多拓展一些其他的销售渠道, 增加多元性; 在销售方式上, 定金 预付——付清尾款——最终发货的“时间慢周期长”的销售模式也在渐渐的转变, 除了新品上 市, 以前的款式还是可以做到现货现发的, 运转速度有了一定的提升。文化产业带动经济转 型, 汉服文化产业的兴起不仅对前向关联产业和后向关联产业有积极的促进作用, 还会带动 当地旅游业的发展。总的来说, 汉服文化产业虽然有一些问题逐渐显露出来有待解决, 但汉 服文化产业的总体趋势是螺旋上升的。

\section{致谢}

本文是国家社科基金一般项目“夏衍翻译与高尔基在中国的传播”（课题编号: 17BWW046）的阶段性成果之一。本文是笔者受老师在课堂上的启发而作, 衣心感谢在写作 中给予建议的老师, 一路走来总有不易, 幸而与君同行!

\section{References}

[1] Congwen Shen, Chinese ancient costume research, Shanghai Bookstore Press, 2011.

[2] Huan Liu,Research on the Industrial Chain Model of Hanfu Culture, Shanghai Normal University, 2015.

[3] Xing Han, Cultural Reflection on the Contemporary Hanfu Revival Movement, Journal of Inner Mongolia University Art College, vol.4, pp. 38-45, 2012. 